\title{
Partidos na República de 1946: Uma Réplica Metodológica
}

Jairo Nicolau

\begin{abstract}
"A principal diferença entre a ciência e a magia é que, no caso da ciência, você comete seus erros em público. Você os exibe para que todos - e não apenas você - aprendam com eles. Desse modo, você se beneficia da experiência de todos os outros, e não somente de seu caminho idiossincrático através do universo de erros. Aliás, é isso que nos torna tão mais inteligente do que qualquer outra espécie". Daniel C. Dennett
\end{abstract}

\begin{abstract}
preciador do bom debate científico, tive o privilégio de ter meu 1 artigo "Partidos na República de 1946: Velhas Teses, Novos Dados" (Dados - Revista de Ciências Sociais, vol. 47, no 1) criticado por Wanderley Guilherme dos Santos no artigo “Velhas Teses, Novos Dados: Uma Crítica Metodológica" (Dados - Revista de Ciências Sociais, vol. 47, $\mathrm{n}^{\mathrm{o}} 4$ ). Seus comentários foram muito úteis: tive que rever uma série de argumentos, perceber que alguns pontos mereciam um tratamento mais aprofundado, e finalmente concluir que temos algumas discordâncias metodológicas. O objetivo deste trabalho é dar continuidade ao debate, analisando e respondendo mais detidamente as críticas de Santos. Para facilitar a leitura, organizei o texto em sete tópicos. A eles:
\end{abstract}

DADOS - Revista de Ciências Sociais, Rio de Janeiro, Vol. 48, n3․ 2005, pp. 589 a 609. 


\section{0 PROPÓSITO DO ARTIGO "PARTIDOS NA REPÚBLICA DE 1946: VELHAS TESES, NOVOS DADOS"}

O artigo "Partidos na República de 1946" foi escrito com dois propósitos. O primeiro foi propor uma nova organização da estatística eleitoral. Vários autores que estudaram o período se lamentaram pelo fato de os dados eleitorais não estarem desagregados por partido. Isso acontecia por que, quando havia coligação eleitoral, a estatística oficial não apresentava os votos de cada partido individualmente.

Minha expectativa, caso conseguisse desagregar os votos das coligações, identificando a votação de cada partido, era que esses dados pudessem servir a outros pesquisadores dedicados ao estudo do sistema partidário da República de 1946. Pensei na possibilidade de avaliar com mais precisão a evolução dos partidos nos estados ou de calcular alguns índices que precisam da votação de cada partido - volatilidade eleitoral e desproporcionalidade votos/cadeiras, por exemplo - para serem calculados.

O caminho para desagregar a votação dos partidos coligados foi feito em duas etapas: a) identificar, em diversas fontes, as ligações dos candidatos a deputado federal com os partidos; b) somar os votos dos candidatos identificados por partido. Depois de exaustivo levantamento, consegui identificar os partidos de $88 \%$ dos candidatos (aí incluídos os que concorriam por partidos não coligados), o que representa $96 \%$ dos votos totais dados aos partidos em todas as eleições. Assim, foi possível montar uma tabela com a votação recebida pelos partidos individualmente entre 1945 e 1962. Até onde eu saiba, pela primeira vez na história dos estudos sobre o tema, uma tabela completa com a votação dos partidos foi organizada.

Tendo conseguido obter a votação de cada partido, uma pergunta surgiu: será que algumas das proposições clássicas sobre o período seriam alteradas pelos novos dados? Escolhi algumas mais conhecidas e resolvi investigar. Esse foi, portanto, o segundo propósito do artigo.

Como já havia deixado claro naquela oportunidade, meu objetivo era verificar se a análise a partir dos novos dados confirmaria ou traria novos elementos aos estudos sobre o sistema partidário do período (Nicolau, 2004:86). Não obstante, Santos enxergou um propósito demasiadamente iconoclasta em meu intento: "Nicolau está seguro que a resolução da incógnita dos votos em coligação trará alterações substanti- 
vas nas hipóteses preservadas pela literatura" (2004:730) ${ }^{1}$. Em nenhum momento disse que meu propósito era refutar teses clássicas, ou que meus dados trariam uma revolução interpretativa sobre o período, nem que falsificariam o estoque de conhecimento sobre o período. Falo em "testar proposições clássicas" (Nicolau, 2004:86), na dúvida se os novos dados "confirmam ou trazem novos elementos" aos estudos (ibidem); e se esses dados "trazem novos elementos para interpretar o sistema partidário da República de 1946" (Nicolau, 2004:90). Sem objetivos explícitos de falsificar dados e tampouco de refutar, procedi inspirado na boa tradição científica: quando na posse de novos dados, testar novamente proposições consolidadas.

\section{A ÊNFASE DO MEU ARTIGO (VOTOS) PODE SER A ÊNFASE DA CRÍTICA DE SANTOS (CADEIRAS)}

Como já assinalei, o intuito primeiro do meu trabalho foi construir uma base de dados com informações ainda desconhecidas, salvo para as eleições de 1945. Mas a identificação dos partidos dos deputados eleitos nas coligações permitiu também organizar uma tabela com a representação dos partidos na Câmara dos Deputados (Tabela 3, p. 90). Como Santos (2004:730-734) mostrou em detalhada análise, os dados da composição da Câmara dos Deputados tal como apresentados por mim têm pequenas discrepâncias com os do Tribunal Superior Eleitoral - TSE. O que explicaria essas pequenas diferenças? Na estatística oficial, as tabelas com a composição partidária da Câmara dos Deputados são acompanhadas da seguinte nota: "Dados cedidos pela Câmara dos Deputados". Daí a minha suspeita de que essas informações se referiam a algum momento posterior à eleição (diplomação, posse ou já durante a atividade parlamentar). Um elemento a mais é que, em 1958, seis deputados aparecem na estatística como "sem partido", o que não poderia ocorrer se os dados se referissem ao momento eleitoral. O fenômeno foi atestado por Santos (2003:144) quando comenta a existência dos trânsfugas, aqueles que "eleitos por legendas sem maior expressão, via a aliança ou coligação com partidos maiores, se registravam no parlamento sob legenda diferente daquela pelo qual concorreram, e não necessariamente ingressando no parceiro maior da coligação que o elegeu".

Embora tivesse feito alguns comentários sobre a composição partidária da Câmara dos Deputados, o objetivo do meu artigo foi analisar a evolução dos partidos no plano eleitoral - seis das oito tabelas apresen- 
tadas no texto referem-se aos votos e não às cadeiras. A razão é simples: os dados realmente novos referiam-se à votação dos partidos, pois o número de cadeiras dos partidos na Câmara já era conhecido e bem analisado pela longa tradição de estudos do período. Não esperava encontrar nada de novo nesse campo. E, como mostrarei mais adiante, só agora me dei conta e encontrei algo de novo.

Além das discordâncias metodológicas, que serão analisadas a seguir, um dos objetivos de Santos foi o de mostrar que meus dados não acrescentam nada de novo ao estoque de conhecimento sobre o sistema partidário da República de 1946. Mas, curiosamente, seus comentários se concentram na análise dos dados sobre a composição da Câmara dos Deputados, e não sobre os votos. Apresentei uma novidade - dados eleitorais e análise baseadas neles - e algo que, em nenhum momento, sustentei ser novidade - dados da composição da Câmara -, já que havia um consenso dos estudiosos sobre a qualidade desses dados. Mas em grande medida o esforço de Santos foi mostrar que não consegui fazer o que não pretendia, ou seja, novas inferências sobre o sistema partidário a partir dos dados das cadeiras da Câmara dos Deputados.

\section{A EVOLUÇÃO DOS PARTIDOS}

Boa parte das minhas observações sobre a evolução dos partidos, baseada na votação, confluiu com a análise clássica sobre o tema feita por Gláucio Soares (1973) e baseada na representação partidária na Câmara dos Deputados. Para avaliar de maneira mais cuidadosa a evolução dos partidos, a Tabela 1 foi organizada. Esta apresenta a diferença em pontos percentuais entre duas eleições sucessivas; a última coluna mostra a diferença entre a primeira e a última eleição realizada no período.

Meus principais comentários sobre a evolução dos partidos foram os seguintes: 1) o PTB* teve um crescimento constante ao longo do período; o maior salto, em pontos percentuais, aconteceu em 1950; 2) a comparação da votação da UDN no começo (1945) e no fim (1962) do período revela um declínio, mas o partido teve um leve crescimento da sua votação entre 1958 e 1962; 3) a comparação da votação do PSD no começo (1945) e no fim (1962) do período também revela um declínio, embora o partido tenha crescido entre 1954 e 1958.

\footnotetext{
* Ver lista de siglas de partidos políticos com os respectivos significados ao final do artigo.
} 
Partidos na República de 1946: Uma Réplica Metodológica

Tabela 1

Diferença em Pontos Percentuais da Votação dos Partidos entre Pares de Eleições

Câmara dos Deputados

\begin{tabular}{l|c|c|c|c|c}
\hline Partidos & $\mathbf{1 9 4 5 - 5 0}$ & $\mathbf{1 9 5 0 - 5 4}$ & $\mathbf{1 9 5 4 - 5 8}$ & $\mathbf{1 9 5 8 - 6 2}$ & $\mathbf{1 9 4 5 - 6 2}$ \\
\hline PSD & $-9,6$ & $-0,2$ & 1,0 & $-3,5$ & $\mathbf{- 1 2 , 3}$ \\
UDN & $-2,5$ & $-2,4$ & $-0,8$ & 1,5 & $\mathbf{- 4 , 2}$ \\
PTB & 8,3 & 0,2 & 1,8 & 4,3 & $\mathbf{1 4 , 6}$ \\
PCB & $-8,7$ & & & & $\mathbf{- 8 , 7}$ \\
PR & 0,3 & 1,5 & 0,2 & $-3,0$ & $\mathbf{- 1 , 0}$ \\
PPS & $-1,8$ & & & & $\mathbf{- 1 , 8}$ \\
PDC & $-0,6$ & 0,5 & 1,4 & 2,5 & $\mathbf{3 , 8}$ \\
PRP & $-0,5$ & & 0,7 & $-0,5$ & $\mathbf{- 0 , 3}$ \\
PRProg. & $-1,2$ & & & & $\mathbf{- 1 , 2}$ \\
PL & 0,7 & 0,9 & $-1,2$ & $-0,2$ & $\mathbf{0 , 2}$ \\
PRD & $-0,6$ & & & & $\mathbf{- 0 , 6}$ \\
PAN & $-0,3$ & & & & $\mathbf{- 0 , 3}$ \\
PSP & 9,7 & 1,5 & $-4,9$ & $-1,4$ & $\mathbf{4 , 9}$ \\
PTN & 2,8 & $-0,6$ & 0,3 & 0,3 & $\mathbf{2 , 8}$ \\
PST & 2,2 & $-1,8$ & 0,7 & 0,6 & $\mathbf{1 , 7}$ \\
PRT & 1,0 & $-0,3$ & & & $\mathbf{0 , 7}$ \\
PSB & 0,5 & 1,1 & 0,7 & $-1,6$ & $\mathbf{0 , 7}$ \\
POT & 0,3 & $-0,3$ & & & \\
PRB & 0,1 & $-0,1$ & & & \\
MTR & & & & 1,0 & $\mathbf{1 , 0}$ \\
\hline
\end{tabular}

Com relação ao desempenho do PSD, alertei para um aspecto: o declínio do partido é mais intenso quando as cadeiras, e não os votos, são tomados como unidade de análise. Entre 1945 e 1962, o PSD caiu 20,4 pontos percentuais na Câmara dos Deputados e 12,4 pontos percentuais em votos ${ }^{2}$. No artigo, chamei a atenção para o efeito produzido pela fórmula eleitoral de 1945, que sobre-representou o PSD (com 42,4\% dos votos o partido obteve 52,8\% das cadeiras). Em 1950, uma fórmula mais proporcional foi adotada, o que gerou uma relação mais próxima entre a votação e a representação dos partidos. A minha conclusão foi que a sobre-repesentação parlamentar de 1945 acabou sugerindo um declínio para o PSD maior do que o encontrado em termos eleitorais.

Em relação ao tópico da evolução dos partidos, Santos (2004:735) concentrou seus comentários nas minhas observações sobre a evolução do 
PTB, particularmente, o forte incremento da votação entre 1945 e 1950. Sugeri que dois fenômenos devem ter contribuído para o incremento da votação do PTB em 1950: "parte deste crescimento, provavelmente, se deveu ao fato de o PCB não participar da disputa, e outra parte aos reflexos da candidatura vitoriosa de Getulio Vargas à Presidência" (Nicolau, 2004:91). Santos criticou a minha sugestão, dizendo que "a qualificação [...] introduz juízo de probabilidades, e não mais de precisão" (2004:735).

Usei o termo "provável", quando apresentei as duas possíveis explicações acima, por uma razão muito simples: nunca poderemos saber com precisão o que motivou os eleitores de 1950 a fazerem opções tão diferentes das que eles haviam feito em 1945 (sem contar que milhares de novos eleitores passaram a votar a partir de 1950). Pesquisas no plano micro - sobretudo as feitas em painel - poderiam trazer evidências mais seguras sobre o que teria motivado as mudanças. Mas temos apenas macrodados (estatística eleitoral) que nos permitem apenas captar tendências, fazer associações estatísticas e calcular alguns índices ${ }^{3}$.

Não quero com isso dizer que não existem explicações mais razoáveis e melhores do que outras. O que fiz foi apresentar duas hipóteses. Santos lembra de outras duas que poderiam ser incluídas para explicar o crescimento do PTB. A primeira credita o crescimento eleitoral do PTB à sua difusão organizacional. Ele tem razão. Tem-se aí uma boa hipótese que precisa ser testada. A segunda vincula o sucesso do PTB à urbanização. Novamente, concordo com Santos. A tese que associa votação dos partidos de esquerda - trabalhistas, comunistas e social-democratas - à urbanização é clássica e também poderia ser analisada. O ideal para testar essas duas hipóteses é que tivéssemos dados com os diretórios dos partidos (hipótese da difusão) e a votação por município (hipótese da urbanização). Contudo, os dados das eleições municipais estão incompletos e padecem dos mesmos problemas dos da Câmara dos Deputados ${ }^{4}$.

Depois de ler os comentários de Santos, percebi que poderia ter feito um teste simples para investigar as possíveis associações entre a votação obtida pelo PTB para a Câmara dos Deputados e a Presidência. O teste de correlação de Pearson com a votação de 21 estados revelou uma associação significativa $(r=0,60)$ entre a votação obtida por Vargas e o desempenho do PTB para a Câmara dos Deputados. Pelas razões apontadas, não se pode dizer que a votação presidencial tenha 
condicionado a votação para Câmara, nem sequer afirmar que os mesmos eleitores votaram simultaneamente nos dois cargos. Mas a existência de correlação é um elemento a mais para analisar a evolução do PTB no período. Porém, será que houve alguma associação entre a votação obtida por João Goulart em 1960 para vice-presidente e o desempenho do PTB nas eleições para a Câmara dos Deputados em 1962? A correlação estatística entre as duas disputas é irrelevante $(r=0,13)$, ou seja, o desempenho do PTB nas eleições para a Câmara dos Deputados em 1962 teve muito pouco a ver com a votação de Goulart em 1960.

\section{0 ÍNDICE DE NACIONALIZAÇÃO}

Os partidos têm, em geral, padrões diferenciados de votação nos distritos eleitorais de um país. No Brasil, por exemplo, sabemos que alguns partidos têm votação dispersa pelo território, enquanto outros têm votação concentrada em um número reduzido de estados. O desafio é estabelecer critérios para avaliar a evolução dos partidos e poder comparar diferentes padrões de distribuição geográfica do voto. Como é possível dizer que alguns partidos estão ficando mais nacionalizados, enquanto outros estão concentrando mais a votação?

Vários autores propuseram índices e medidas com tal propósito. Não se trata aqui de discutir cada um deles, o que já foi feito em detalhes por outros autores 5 . Mas é importante lembrar de duas premissas básicas para a utilização dos índices em qualquer área do conhecimento. A primeira: eles são instrumentos matemáticos criados para sumarizar informações e descrever padrões de dados; por isso, todos eles produzem algum grau de empobrecimento em relação ao fenômeno que é estudado. A segunda: os índices têm limites matemáticos inerentes à sua construção (como será exemplificado na próxima seção). O que todo cientista social busca é um índice capaz de minorar ao máximo esses dois efeitos.

Objetivando avaliar o padrão de votação dos partidos nas eleições para a Câmara dos Deputados, utilizei um índice bastante conhecido nos estudos eleitorais, a saber: $\mathrm{o}$ indice de desigualdade regional cumulativo, proposto por Derek Urwin (1983). O índice simplesmente compara o percentual da votação que um partido obteve em cada distrito eleitoral (unidades da Federação, no caso do Brasil), em relação à votação total obtida no país, com o percentual do eleitorado do estado sobre o eleitorado do país. As diferenças encontradas em cada unidade são so- 
madas, desconsiderando-se os sinais positivos e negativos, obtendo-se valores que variam de 0 a 100 (ou de 0 a 1 , se o número obtido for divido por 100); quanto mais próximo de 100, mais concentrada é a votação do partido.

Os exemplos abaixo ilustram o cálculo do índice de desigualdade regional cumulativa para dois diferentes partidos (Azul e Vermelho).

Exemplo I

Partido Azul

\begin{tabular}{|l|c|c|}
\hline Estados & $\begin{array}{c}\text { \% da População } \\
\text { do Eleitorado do } \\
\text { Estado }\end{array}$ & $\begin{array}{c}\text { \% da Votação do } \\
\text { Partido Azul em } \\
\text { cada Estado }\end{array}$ \\
\hline 1 & 35 & 70 \\
2 & 25 & 20 \\
3 & 15 & 10 \\
4 & 15 & 5 \\
5 & 5 & 0 \\
\hline
\end{tabular}

Exemplo II

Partido Vermelho

\begin{tabular}{|l|c|c|}
\hline Estados & $\begin{array}{c}\text { \% da População } \\
\text { do Eleitorado do } \\
\text { Estado }\end{array}$ & $\begin{array}{c}\text { \% da Votação do } \\
\text { Partido Vermelho } \\
\text { em cada Estado }\end{array}$ \\
\hline 1 & 35 & 40 \\
2 & 25 & 35 \\
3 & 15 & 10 \\
4 & 15 & 10 \\
5 & 5 & 5 \\
\hline
\end{tabular}

Uma rápida observação das duas tabelas já leva o leitor suspeitar que o Partido Vermelho tem um padrão de voto mais concentrado. Mas vejamos como o índice é calculado. Para o Partido Azul: | 35-70 | + | 25-20 $|+| 15-10|+| 15-5|+| 5-0 \mid=60$, ou 0,60. Se fizermos a mesma operação para o Partido Vermelho, o valor será igual a 25, ou 0,25. A aplicação do índice de desigualdade regional cumulativa revela que, realmente, o Partido Azul tem um padrão de votação mais concentrado $(0,60)$ do que o Vermelho $(0,25)$.

A discussão sobre qual índice utilizar, para mensurar a dispersão/concentração dos partidos, é importante. Mas provavelmente a maior no- 
vidade do meu trabalho tenha sido não a medida que foi utilizada, mas o fato de avaliar a evolução dos partidos no âmbito eleitoral. Acredito que a análise dos votos é melhor para analisar a evolução dos partidos uma vez que a representação desses na Câmara dos Deputados é contaminada pelos efeitos do sistema eleitoral - coligações, magnitude do distrito, fórmula eleitoral. No caso brasileiro, um partido pode ficar mais nacionalizado em termos eleitorais, mas não traduzir esse crescimento em representação parlamentar, simplesmente por que ele perdeu cadeiras nas coligações ou não conseguiu atingir o quociente eleitoral em alguns estados.

Se tomarmos o patamar de 0,33 do indice de concentração regional como critério para considerar um partido como regional, veremos que apenas PSD, PTB e UDN podem ser considerados partidos nacionais; embora não houvesse nenhuma tendência clara na evolução do índice para esses partidos ${ }^{6}$. Assim, a proposição de Olavo Brasil de Lima Junior (1983:127) sobre a nacionalização generalizada não foi confirmada pela análise do desempenho eleitoral dos partidos. Como mostrei no meu texto (Nicolau, 2004:93), Santos (2003) já havia discordado de Lima Junior (1983) e defendido que a nacionalização era um processo que atingiu apenas os três maiores partidos. Portanto, neste ponto há convergência entre os meus dados e as conclusões de Santos.

Santos passa quatro páginas, mais precisamente da 736 à 740, criticando possíveis imperfeições técnicas do índice de desigualdade regional cumulativa e de outras medidas utilizadas para calcular a nacionalização dos partidos. Além disso, defende a superioridade da medida utilizada por ele, que é bastante simples: "o número necessário de unidades da Federação para que a soma dos votos nela conquistado atingisse $50 \%$ do total de votos partidários: quanto maior o número de unidades da Federação necessárias para alcançar os 50\%, maior o grau de nacionalização do partido" (Santos, 2004:739).

Observe que Santos na explicação acima fala que seu índice é calculado sobre os votos. Mas a pergunta óbvia é: como calcular a nacionalização tomando a votação dos partidos com unidade de análise se elas não estavam discriminadas antes que o meu trabalho viesse a público? Na realidade, no seu livro sobre o período, Santos não utilizou a votação, nem poderia, mas o "número de estados necessários para alcançar mais de $50 \%$ do total de representação partidária na Câmara dos Depu- 
tados" (Santos, 2003:150-151). Seus dados revelam que esse patamar variou entre um e seis estados.

Tanto o índice proposto por Santos (2003) quanto o utilizado no meu trabalho têm virtudes e defeitos ${ }^{7}$. O aspecto que enfatizei não foi a forma de mensurar a nacionalização, mas a nova unidade de análise (votos). Como já a pontei, os resultados de minha análise convergiram com os de Santos, baseados exclusivamente na distribuição das bancadas dos partidos na Câmara dos Deputados. Mas Santos preferiu acentuar o fato de preferirmos medidas diferentes a assinalar que meus dados convergiram com as análises feitas por ele.

\section{OS ÍNDICES DE FRACIONALIZAÇÃO (F) E NÚMERO EFETIVO DE PARTIDOS (F)}

O propósito desta seção é fazer alguns comentários sobre dois índices muito utilizados pela ciência política, particularmente nos estudos eleitorais. Este esforço é fundamental para a compreensão da seção seguinte, onde tratarei mais especificamente dos comentários de Santos sobre o assunto.

Nos anos 1940, um índice foi criado por economistas com o intuito de mensurar a concentração de firmas em um determinado setor. Imagine-se, por exemplo, a distribuição de empresas no mercado de automóveis. Como poderemos mensurar o padrão de concentração/dispersão, levando em conta a fatia de mercado que cada empresa controla? ${ }^{8}$. $\mathrm{O}$ indice de concentração de Herfindal-Hirschman $(\mathrm{HH})$, como ficou conhecido em homenagem aos seus autores, é calculado de maneira bastante simples: Índice de concentração de Herfindal-Hirschman (HH): $\Sigma \mathrm{p}^{2} i$ (onde pi é a proporção do mercado controlado pela empresa pi).

O índice varia de 0 a 1; quanto mais próximo de 1, maior a concentração. Imagine-se, por exemplo, o mercado de refrigerantes, com cinco firmas, cada uma delas com a seguinte fatia: $40 \%, 30 \%, 15 \%, 10 \%$ e $5 \%$. $\mathrm{O}$ indice $\mathrm{HH}$ seria calculado da seguinte forma: $(0,40 \times 0,40)+(0,30 \mathrm{x}$ $0,30)+(0,15 \times 0,15)+(0,10 \times 0,10)+(0,05 \times 0,05)$. O resultado é igual a 0,29 . Índices inspirados no $H H$ têm sido utilizados em diversas disciplinas. Na sociologia, por exemplo, tem sido empregado para medir consenso, na biologia para mensurar o grau de diversidade (Monroe, 2000). 
O cientista político norte-americano Douglas Rae (1967) sugeriu um novo índice para mensurar a concentração/dispersão de votos em uma eleição, ou das cadeiras no Legislativo. Como a preocupação de Rae era mensurar a dispersão, ele simplesmente inverteu o resultado do $H H$, subtraindo-o de 1: Índice de fracionalização de Rae (F): $1-H H$

Se no lugar das firmas do exemplo anterior, imaginarmos cinco partidos com as mesmas distribuições de votos no Legislativo, teríamos um índice F de 0,61 (1-0,29). O índice de Rae varia de zero (em um Parlamento, por exemplo, um partido controla todas as cadeiras) a 1 (cada cadeira do Parlamento seria ocupada por um partido diferente). O índice F é interpretado em termos de pares discordantes, revelando qual é a probabilidade de que dois deputados de um Parlamento pertençam a partidos diferentes. No exemplo apresentado acima é de $0,61^{9}$, ou seja, se escolhermos dois deputados aleatoriamente, existe $61 \%$ de probabilidade de que eles sejam de partidos diferentes.

O indice $F$ foi bastante utilizado na ciência política em importantes trabalhos comparativos da década de 1970, entre eles o influente Partyand Party Systems, de Giovani Sartori, publicado em $1976^{10}$. Os cientistas políticos Jan-Erik Lane e Svante Ersson (1994:113-135) utilizaram a medida de fracionalização para mensurar a dispersão étnica e religiosa dos países.

Mais recentemente, Marku Laakso e Rein Taagepera (1979) propuseram um novo índice, o número efetivo de partidos $(\mathrm{N})$, para mensurar a dispersão/concentração. $\mathrm{O} \mathrm{N}$ também toma o HH como base para cálculo: Número efetivo de partidos de Laakso e Taagepera (N): 1/ HH

No exemplo anterior, com cinco partidos $(40 \%, 30 \%, 15 \%, 10 \%$ e $5 \%)$ o número efetivo de partidos seria igual a 3,5. Tanto $\mathrm{F}$ como $\mathrm{N}$ são variações sobre o HH. Mas, desde os anos 1980, este índice tem sido utilizado com mais freqüência pela ciência política, particularmente, nos estudos comparativos sobre sistemas eleitorais e sistemas partidários (Taagepera e Shugart, 1989; Lijphart, 1994; 2003; Norris, 2004; Farrel, 2001; Cox, 1997). Qual seria a razão da predileção dos cientistas políticos pelo indice do número efetivo de partidos? Diversos autores (Sartori, 1982:35; Taagepera e Shugart, 1989:39; Lijphart, 1994:69) consideram o índice mais fácil de visualizar em termos concretos. Vale a pena reproduzir uma passagem escrita por Arend Lijphart sobre o assunto: 
“A grande vantagem de $\mathrm{N}$ é que ele pode ser visualizado mais facilmente como número de partidos do que o índice abstrato de Rae. Em um sistema bipartidário, com dois partidos igualmente fortes, o número efetivo é exatamente $2.00(\mathrm{~F}=0,50)$. Se um dos partidos é consideravelmente mais forte do que o outro, como, por exemplo, com votos ou cadeiras de $70 \%$ e 30\%, o número efetivo de partidos é de 1.72 - em acordo com nosso julgamento intuitivo de que estamos nos movendo de um sistema bipartidário puro em direção a um sistema unipartidário ( $\mathrm{F}=$ 0,42). Do mesmo modo, com um sistema com três partidos exatamente iguais, a fórmula do número efetivo é de 3.00 ( $F=0,67)$. Se um desses partidos é mais fraco do que os outros dois, o número efetivo ficará em algum lugar entre 2.00 e 3.00, dependendo da força do terceiro partido (F estaria entre 0,50 e 0,67)" (Lijphart, 1994:69) ${ }^{11}$.

O principal limite dos índices $\mathrm{HH}, \mathrm{F}$ e $\mathrm{N}$ é que, como são baseados nos quadrados dos valores de cada unidade, eles tendem a superestimar o impacto das maiores unidades, enquanto o das menores é subestimado. Já na década de 1970, Sartori apontava esse aspecto, quando comentava os limites do índice F:

“Sem dúvida, a fracionarização de Rae é uma medida do número e, mais ainda, do tamanho dos partidos. Mas a medida, na verdade, supervaloriza os partidos maiores e condensa demasiado rapidamente os partidos menores - como é evidente, já que as porcentagens partidárias são quadrados. Por exemplo, um partido cujo tamanho é de $40 \%$ contribui com $0,16 \%$ para a soma dos quadrados, ao passo que um partido de $10 \%$ contribui apenas com $0,01 \%$ (na verdade, um valor desproporcionalmente baixo)" (Sartori, 1982:337).

\section{SANTOS E OS ÍNDICES DE FRACIONALIZAÇÃO (F) E DO NÚMERO EFETIVO DE PARTIDOS (N)}

Santos (2004:740-752) faz uma longa discussão sobre os índices F e N. Não cabe resumir aqui todos os tópicos - alguns altamente técnicos mobilizados pelo autor. Mas quero destacar um mais geral: em diversas passagens, ele procura demonstrar a fragilidade do índice $\mathrm{N}$ e a maior precisão do índice $\mathrm{F}^{12}$. No meu entender, a principal crítica feita por Santos ao indice $N$ refere-se à má - e incomum - interpretação dos seus valores. Como visto anteriormente, os valores de $\mathrm{N}$ são um construto matemático. Por isso, não é possível fazer o caminho de volta ao mundo partidário e identificar quais partidos são aqueles. É um equí- 
voco grave, por exemplo, sabendo que, em um parlamento, o N é igual a 3,2, tentar identificar quais seriam os três "partidos efetivos"13. Por isso, o índice é do número efetivo, e não de partidos efetivos ${ }^{14}$. Mas pode-se dizer, por exemplo, que a dispersão partidária do Brasil $(\mathrm{N}=8,3)$ é maior do que a da Espanha $(\mathrm{N}=2,7)$, mas menor do que da Papua Nova Guiné $(\mathrm{N}=10,8)$. Daí a minha total concordância com a indagação de Santos (idem:751): "A propósito, o NEP que acompanhou todo o período 1945-62 variou de 4 a 4,3; quais 4 entre os 16 do sistema partidário brasileiro? De um contrafactual aritmético nada pode ser derivado substantivamente sobre o mundo extra-aritmético".

Em resumo, creio que o problema do índice $\mathrm{N}$ derive mais de uma má interpretação do que de uma limitação técnica inerente à sua construção - embora, como salientei acima, ela exista.

Como tentei mostrar na seção anterior, N e F são ambos derivados de HH e têm sido utilizados para medir a concentração/dispersão das unidades de uma dada população. Por razões específicas, os pesquisadores têm escolhido um ou outro para utilizar em suas investigações. Ao contrário da interpretação corrente - a qual me filio - que sustenta que ambos os índices comportam a mesma informação, Santos enxerga diferenças fundamentais entre os dois ${ }^{15}$. Essa é, provavelmente, a principal diferença metodológica entre nós ${ }^{16}$.

Mas Santos afirma no resumo do seu artigo que minhas teses são inválidas, inclusive o uso que faço do "conceito do número de partidos efetivos". Na verdade, não utilizo o conceito, uso o índice. Fiquei pensando se foi minha redação infeliz na página 97 , quando desloquei o adjetivo "efetivo" para o lado do substantivo "partido" (no lugar de 4,8 partidos efetivos em média, deveria ter escrito a média do $\mathrm{N}=4,8$ ), que levou Santos a ter creditado a mim o emprego inválido do conceito ${ }^{17}$. Apesar da redação não muito clara, em nenhum momento do texto cometo o equívoco de dizer que conhecer um dado $\mathrm{N}$ permitiria identificar quais eram os partidos relevantes, efetivos, ou que nome se queira dar aos partidos mais importantes.

Retomo agora o que disse no meu artigo sobre a evolução da fragmentação partidária no âmbito eleitoral durante o período $1945-62^{18}$. Em três passagens do seu texto (todas reproduzidas por mim) sobre a República de 1946, Santos diz que houve um aumento da fragmentação partidária na Câmara dos Deputados. Minha intenção foi testar se essa proposição se sustentava com os novos dados. Por isso, utilizei o N. Os 
valores encontrados para o $\mathrm{N}$ (eleitoral) são os seguintes: $1945(4,7)$, $1950(4,7), 1954(4,9), 1958(4,8), 1962(4,7)$. Minha conclusão é que não se pode dizer que estava havendo uma ampliação da dispersão (fragmentação) partidária no plano eleitoral. Poder-se-ia medir de outro jeito, utilizando o F, e encontrar-se-ia os seguintes valores: $1945(0,726)$, $1950(0,783), 1954(0,794), 1958(0,790)$ e $1962(0,789)$. Dados que confirmam a proposição: não estava havendo aumento da fragmentação partidária no plano eleitoral.

Quanto à dispersão na Câmara dos Deputados, vale observar os meus cálculos comparativamente aos de Santos, que utiliza os dados tradicionais do TSE:

\begin{tabular}{|l|c|c|c|c|c|}
\hline & $\mathbf{1 9 4 5}$ & $\mathbf{1 9 5 0}$ & $\mathbf{1 9 5 4}$ & $\mathbf{1 9 5 8}$ & $\mathbf{1 9 6 2}$ \\
\hline Nicolau & 2,7 & 4,1 & 4,3 & 4,4 & 4,5 \\
\hline Santos & 3,4 & 4,3 & 4,6 & 4,5 & 4,5 \\
\hline
\end{tabular}

Fonte: Nicolau (2004:99); Santos (2003:77).

Só agora percebi que nós dois erramos em nossa leitura dos dados. Afirmei que que não houve uma estabilidade da fragmentação no plano parlamentar (Nicolau, 2004:98), e meus dados indicam que houve um leve crescimento. Em contrapartida, Santos afirmou que houve aumento da fragmentação parlamentar, e seus dados indicam estabilidade. Assim, retifico o que disse no meu artigo original: Santos está correto em dizer que houve um aumento da fragmentação parlamentar no período.

\section{A IMPORTÂNCIA DAS PESQUISAS EQUIVOCADAS NA CIÊNCIA}

Gostaria de terminar manifestando concordância total com uma passagem de Santos em que ele enfatiza o papel do insucesso nos projetos de pesquisa: "Espero ter ficado claro, entretanto, que nenhum resultado de pesquisa é descartável. Um projeto fracassado deixa como saldo positivo certo acréscimo no estoque das proposições equivocadas, o que nos permite rejeitá-las, e esclarecimentos onde havia dúvidas" (2004:757).

Já havia aprendido com outros autores (King et alii, 1994, por exemplo), que os cientistas sociais têm uma tendência de ocultar seus erros e trazer a público somente os resultados bem-sucedidos. Variáveis relevantes teoricamente são eliminadas da análise por não terem sido estatisticamente significativas, testes fracassados são banidos e, muitas vezes, 
a pesquisa dá impressão que tudo sucedeu de forma demasiadamente certa com os dados. Pior ainda é quando um pesquisador descobre que seu trabalho já publicado continha alguns erros. Quem não viu um colega desolado por descobrir uma pequena imprecisão em um artigo? Ou a angústia de outro, quando se deu conta que sua análise foi superada por outra mais consistente? Quem já não se sentiu abatido por ter seus erros apontados em críticas alheias? Ao contrário dos outros cientistas, temos dificuldades em admitir que um componente fundamental do trabalho científico é que ele é provisório e muitas vezes é superado por outros.

Independentemente de como o meu artigo venha a ser avaliado por outros colegas, talvez ele possa ter dado uma pequena contribuição aos estudos sobre os partidos na República de 1946. Alguns dos principais estudiosos do período, como Gláucio Soares, Maria do Carmo Campello de Souza, Olavo Brasil de Lima Junior e Antônio Lavareda, imaginavam que a votação desagregada por partido poderia trazer evidências mais precisas sobre a evolução do sistema partidário. Os dados estão aí. Uma porta a mais se fechou. O que não é pouco para a produção de explicações mais precisas sobre o período.

(Recebido para publicação em abril de 2005)

(Versão definitiva em julho de 2005)

\section{NOTAS}

1. Santos superestima os meus objetivos em diversas passagens. Na página 748, por exemplo, ele diz que tenho três objetivos: "rejeitar hipóteses da literatura sobre a evolução da força dos partidos, ao longo do período 1945-62; rejeitar outras sobre possíveis avanços na nacionalização dos partidos; e, finalmente, reconsiderar profundamente teses correntes sobre a fracionalização do sistema partidário brasileiro".

2. De acordo com a tabela da estatística tradicional, utilizada por Santos, a diferença é de 24 pontos percentuais (2004:733).

3. Para uma discussão sobre as mudanças eleitorais nos planos macro e micro, ver Lane e Ersson (1997).

4. Os dados com a votação dos partidos para a Câmara dos Deputados do período 1945-62 nos municípios não estão disponíveis nas estatísticas do TSE. Para as elei- 


\section{Jairo Nicolau}

ções municipais, a votação dos partidos também não está discriminada, quando eles concorrem coligados. Apesar dessas dificuldades, alguns desses dados foram analisados por Gláucio Soares (2001:67-76). Ele mostrou, particularmente, como cresceu, entre 1947-48 e 1954-55, o número de municípios nos quais o PTB disputou as eleições.

5. Um ótimo balanço pode ser encontrado em Jones e Mainwaring (2003) e Caramani (1996).

6. Este patamar foi sugerido por Urwin (1983) no seu estudo sobre a nacionalização dos partidos europeus.

7. A simples contagem do número de unidades da federação em que os partidos recebem $50 \%$ da sua bancada têm dois problemas. O primeiro, já comentado, é que as bancadas - por conta dos efeitos do sistema eleitoral, de punir ou recompensar os partidos - podem não expressar o processo de evolução eleitoral de um partido. O segundo problema é que o índice não é monotônico: o fato de o partido ampliar sua representação para mais um estado não implica necessariamente que o valor da medida se alterará.

8. Sobre o HH, ver Taagepera e Shugart (1989:79).

9. Conheço apenas uma crítica (Monroe, 2000:116) a esta interpretação do índice F. Segundo o autor, só faz sentido analisar o índice com probabilidade de extrair pares discordantes em grandes populações; por isso, deve-se ter o cuidado na interpretação do índice para pequenos grupos como Legislativos. Mas, o autor não apresenta evidências técnicas mais detalhadas sobre o tema.

10. Ver Sartori (1982), especialmente, o capítulo 9, onde ele apresenta o índice F para a Câmara dos Deputados de 68 países.

11. As razões de Lijphart (1994:70) são condensadas na seguinte passagem: "Por que o número efetivo de partidos é a medida mais pura do número de partidos, por que ela tem se tornado a medida mais amplamente utilizada, por que as medidas alternativas são similares na maioria dos aspectos, e por último, mas não menos importante, por que ela é muito mais simples em termos computacionais que as alternativas, ele será a medida do número de partidos usada neste estudo". Taagepera e Shugart (1989:80) também pensam da mesma maneira: "Qual dos três índices nós devemos usar? HH é mais simples de calcular. Nós freqüentemente gostamos que nossos índices variem de 0 a 1 , e tanto o $\mathrm{HH}$ como o $\mathrm{F}$ têm esta propriedade. O número de componentes $\mathrm{N}$ é o mais fácil de visualizar em termos técnicos: $\mathrm{N}=2,28$ diz-nos diretamente que existem dois grandes partidos e definitivamente menos que três grandes partidos, enquanto $\mathrm{HH}=0,439$ ou $\mathrm{F} 0,561 \mathrm{diz}$ a mesma coisa menos diretamente". Segundo os autores (idem:81), o $\mathrm{N}$ também permitiria mais versatilidade para testes estatísticos mais sofisticados.

12. Qualquer teste com os dados revela que os dois índices estão absolutamente associados. Na Tabela 4 (Santos, 2004:753), ele apresenta dados do F e do N entre 1945 e 1986. A correlação entre eles é de: 0,998!; só não é igual a 1 por conta dos arredondamentos dos números.

13. Já observei que este erro é comum entre os alunos pouco familiarizados com o índice. Mas não me lembro de ter visto, em qualquer trabalho sério, esta transposição simples do mundo abstrato do índice $\mathrm{N}$ para o mundo real das eleições e dos Legislativos. Boa parte dessa confusão talvez se deva a uma tradução equivocada - no lugar 
de número efetivo de partidos, alguns autores brasileiros utilizaram número de partidos efetivos. Eu próprio já adotei a tradução que, hoje, considero menos precisa. Ver Nicolau (1996).

14. O índice $\mathrm{N}$ também vem sendo largamente utilizado nos estudos sobre sistemas partidários no Brasil.

15. Além das críticas metodológicas feitas no seu artigo, Santos também trata separadamente os índices $\mathrm{N}$ e $\mathrm{F}$ no seu trabalho, chegando a utilizar os dois como variáveis independentes. Ver, por exemplo, Santos (2003:79), onde ele utiliza N e F como variáveis independentes. Creio não ser coincidência que os principais estudiosos do tema escolhem apenas um destes índices para utilizar em seus trabalhos.

16. Além dos tradicionais $\mathrm{Ne} \mathrm{F}$, Santos utiliza outros dois índices que são variações do F, a saber: o indice de fracionalização máxima (Fmax), que mede a fracionalização máxima em um parlamento em função do número de partidos e das cadeiras; e o indice de fragmentação, que é o resultado da divisão de F por Fmax, ou seja, o índice revela quão próximo a fracionalização de um dado parlamento está de uma situação hipotética de dispersão total. Santos (2004:748) chama a atenção para o fato de que, apesar de discutir o problema da fragmentação, em nenhum momento, apresento índices sobre F, Fmax e Frag. Creio que esses dois índices acrescentem pouco para o entendimento da dispersão/concentração de um dado parlamento. Em termos empíricos, pouco importa saber qual seria a fracionalização máxima, ou quanto a fracionalização real dista desta hipotética medida. Existem muitas questões de pesquisas reais para as quais alguma medida de dispersão pode ser útil: Qual é o impacto do sistema eleitoral para reduzir a fragmentação eleitoral? Existe relação entre a fragmentação social e a fragmentação partidária? Existe alguma relação entre padrão de dispersão parlamentar e dispersão do ministério? Qual a relação entre fragmentação parlamentar e durabilidade dos gabinetes? Para nenhuma delas o uso das duas medidas hipotéticas acima faz qualquer sentido analítico.

17. Depois de observar que Santos já fez o mesmo em seu trabalho, percebi que essa não podia ser a razão. Por exemplo, o autor escreve "reduções no número de partidos efetivos", e não "redução do número efetivo de partidos" (Santos, 1987:52); no mesmo trabalho, escreve literalmente "número de partidos efetivos" mais de uma vez quando se refere ao índice N (idem:106).

18. Segundo Santos (2004:748): “Nicolau não está usando o conceito de 'fragmentação' tal como existe na literatura". Não sei qual literatura a que Santos se refere, mas por fragmentação partidária entendo os diferentes padrões de concentração e dispersão do voto dos eleitores em uma dada eleição ou da representação em um dado legislativo. Os índices $\mathrm{HH}, \mathrm{F}$ e N são algumas das opções possíveis para mensurar a fragmentação partidária. Escrevi um livro que trata exclusivamente do tema (ver Nicolau, 1996). 


\section{Jairo Nicolau}

\section{REFERÊNCIAS BIBLIOGRÁFICAS}

CARAMANI, Daniele. (1996), "The Nationalisation of Electoral Politics: A Conceptual Reconstruction and a Review of the Literature". West European Politics, vol. 19, no 2, pp.205-224.

COX, Gary W. (1997), Making Voting Counts: Strategic Coordination in the World's Electoral Systems. Cambridge, Cambridge University Press.

FARREL, David M. (2001), Electoral Systems: A Comparative Introduction. New York, Palgrave.

JONES, Mark e MAINWARING, Scott. (2003), “The Nationalization of Parties and Party Systems: An Empirical Measure and Application to the Americas". Party Politics, vol. 9, nํㅡ 2, pp. 139-166.

KING, Gary, KEOHANE, Robert. O. e VERBA, Sidney. (1994), Designing Social Research. Princeton, Princeton University Press.

LAAKSO, Marku e TAAGEPERA, Rein. (1979), “'Effective' Number of Parties: A Measure with Application to West Europe". Comparative Political Studies, vol. 12, no 1, pp.3-27.

LANE, Jan-Erik e ERSSON, Svante O. (1994), Comparative Politics: An Introduction and New Approach. Cambridge, Polity Press.

. (1997), Parties and Voters: What Creates the Ties?" Scandinavean Political Studies, vol. 20, no 2, pp. 179-196.

LIJPHART, Arendt. (1994), Electoral Systems and Party Systems. Cambridge, Cambridge University Press.

. (2003) [1999], Modelos de Democracia: Desempenho e Padrões de Governo em 36 Países. Rio de Janeiro, Civilização brasileira.

LIMA JUNIOR, Olavo Brasil de. (1983), Os Partidos Políticos Brasileiros - A Experiência Federal e Regional: 1945/64. Rio de Janeiro, Graal.

MONROE, Burt L. (2000), "Fractionalization Index", in R. Rose (ed.), International Encyclopedia of Elections. Washington, CQ Press, pp. 116-117.

NICOLAU, Jairo. (1996), Multipartidarismo e Democracia: Um Estudo sobre o Sistema Partidário Brasileiro (1985-94). Rio de Janeiro, Fundação Getulio Vargas Editora.

(2004), “Partidos na República de 1946: Velhas Teses, Novos Dados". Dados, vol. 47, no 1, pp. 85-129.

NORRIS, Pippa. (2004), Electoral Engineering: Voting Rules and Political Behavior. Cambridge, Cambridge University Press.

RAE, Douglas. (1967), The Political Consequences of Electoral Laws. New Haven, Yale University Press.

SANTOS, Wanderley Guilherme dos. (1987), Crise e Castigo: Partidos e Generais na Política Brasileira. Rio de Janeiro, Vértice.

. (2003), O Cálculo do Conflito: Estabilidade e Crise na Política Brasileira. Belo Horizonte/Rio de Janeiro, Editora UFMG/IUPERJ. 


\section{Partidos na República de 1946: Uma Réplica Metodológica}

_ (2004), “Velhas Teses, Novos Dados: Uma Análise Metodológica". Dados, vol. 47, no 4 , pp. 729-762.

SARTORI, Giovanni. (1982) [1976], Partidos e Sistemas Partidários. Rio de Janeiro, Zahar Editores.

SOARES, Gláucio Ary Dillon. (1973), Sociedade e Politica no Brasil. São Paulo, Difel. . (2001), A Democracia Interrompida. Rio de Janeiro, Fundação Getulio Vargas Editora.

TAAGEPERA, Rein e SHUGART, Matthew. S. (1989), Seats and Votes. New Haven, Yale University Press.

URWIN, Derek W. (1983), “Harbinger, Fossil or Fleabite? 'Regionalism' and the West European Party Mosaic", in H. Daalder e P. Mair (eds.), Western European Party Systems: Continuity and Change. London, Sage, pp. 221-256. 
LISTA DE SIGLAS DE PARTIDOS POLÍTICOS

MTR - Movimento Trabalhista Renovador

PAN - Partido dos Aposentados da Nação

PCB - Partido Comunista Brasileiro

PDC - Partido Democrata Cristão

PL - Partido Liberal

POT - Partido Orientador Trabalhista

PPS - Partido Popular Sindicalista

PR - Partido Republicano

PRB - Partido Ruralista Brasileiro

PRD - Partido Republicano Democrático

PRP - Partido da Representação Popular

PRProg - Partido Republicano Progressista

PRT - Partido Reformador Trabalhista

PSB - Partido Socialista Brasileiro

PSD - Partido Social Democrático

PSP - Partido Social Progressista

PST - Partido Social Trabalhista

PTB - Partido Trabalhista Brasileiro

PTN - Partido Trabalhista Nacional

UDN - União Democrática Nacional 


\begin{abstract}
Political Parties in the Republic of 1946: A Methodological Reply

This article discusses some questions raised by Wanderley Guilherme dos Santos in the article "Old Theses, New Data: A Methodological Analysis", published in Dados - Revista de Ciências Sociais. The paper focuses particularly on an important methodological discussion, namely the measurement of political events. Two topics in the party system are specifically explored: the dispersion of Congressional voting and power (fragmentation rates) and territorial dispersion of voting (partisan nationalization rates).
\end{abstract}

Key words: political parties; elections; Chamber of Deputies

\title{
RÉSUMÉ
}

Les Partis dans la République de 1946: Une Réplique Méthodologique

Dans cet article, on discute des questions suggérées par Wanderley Guilherme dos Santos dans son texte "Vieilles Thèses, Nouvelles Données: Une Analyse Méthodologique", paru dans Dados - Revista de Ciências Sociais. Son texte présente particulièrement une discussion méthodologique importante, celle de comment mesurer les événements politiques. Deux aspects du système des partis sont examinés dans le détail: la dispersion des voix/le pouvoir parlementaire (indices d'éparpillement) et la dispersion territoriale des voix (indices de nationalisation des partis).

Mots-clé: les partis; élections; Chambre des Députés 